\title{
Partial Pituitary Ablation with Implants of Gold-198 and Yttrium-90 for Cushing's Syndrome with Associated Adrenal Hyperplasia
}

\author{
M. HARTOG, ${ }^{*}$ B.M., M.R.C.P. ; F. DOYLE, $\dagger$ M.B., B.SC., F.F.R., D.M.R.D. ; K. FOTHERBY, $\ddagger$ \\ RUSSELL FRASER,* M.D., F.R.C.P. ; G. F. JOPLIN,* M.B., M.R.C.P.
}

Brit. med. F., 1965, 2, 392-395

There is still considerable controversy over the best method of treating Cushing's syndrome when it is due to bilateral adrenal hyperplasia. The majority of such patients are treated by either total or subtotal adrenalectomy. These, however, are not only major operations but they often lead to a lifelong dependence on corticosteroids, and are sometimes followed by progression of a pituitary tumour which requires further treatment (Sprague et al., 1961). Some remission has also been reported in about half of the patients given conventional deep $x$-ray therapy to the pituitary (Dohan et al., 1957 ; Soffer et al., 1961), and more often when this was supplemented by unilateral adrenalectomy (Soffer et al., 1961). In the hope of obtaining good responses more often from a higher irradiation dose to the pituitary, we have treated our patients for the past five years by partial pituitary ablation by means of implantation of radioactive material into the pituitary. This allows the delivery of a greater dose of irradiation to the pituitary than is possible by external deep $x$-ray therapy, yet without incurring extra risk of damage to the surrounding structures. Satisfactory results from more intensive radiotherapy to the pituitary have also been reported by Linfoot et al. (1963), using heavy-particle beams, and by Molinatti et al. (1960), also using ${ }^{90} \mathrm{Y}$ implants. This paper supplements our previous communication (Joplin et al., 1961), and also reviews the diagnostic procedures which can be used to establish the diagnosis.

Patients Treated.-During the period of this review all of the 22 patients diagnosed as suffering from Cushing's syndrome shown to be pituitary-dependent were treated by

\begin{tabular}{|c|c|c|c|c|c|}
\hline \multirow{3}{*}{ Final Diagnosis } & \multirow{3}{*}{$\begin{array}{l}\text { No. of } \\
\text { Patients }\end{array}$} & \multicolumn{4}{|c|}{$\begin{array}{c}\text { No. of Subjects whose Urinary 17-oxogenic } \\
\text { Steroid Shows : }\end{array}$} \\
\hline & & \multirow[b]{2}{*}{$\begin{array}{c}\text { High } \\
\text { Basal } \\
\text { Values } \\
(>18 \mathrm{mg} . / \\
24 \mathrm{hr} .)\end{array}$} & \multicolumn{2}{|c|}{$\begin{array}{l}\text { Abnormal Dexa- } \\
\text { methasone Tests }\end{array}$} & \multirow[b]{2}{*}{$\begin{array}{c}\text { Rise on } \\
\text { Meto- } \\
\text { pironet } \\
\text { (500 mg. } \\
\text { 4-hourly) }\end{array}$} \\
\hline & & & $\begin{array}{l}\text { (2-4 mg./ } \\
24 \mathrm{hr} .) \\
\text { Suppres- } \\
\text { sion In- } \\
\text { complete } \\
\text { or Nil* }\end{array}$ & $\begin{array}{l}\text { (8 mg.l } \\
24 \mathrm{hr} .) \\
\text { No } \\
\text { Sup- } \\
\text { pression }\end{array}$ & \\
\hline \multicolumn{6}{|l|}{$\begin{array}{l}\text { Adrenal hyperplasia: } \\
\text { Obvious pituitary }\end{array}$} \\
\hline $\begin{array}{cc}\text { tumour } & \cdots \\
\text { Others } & \cdots \\
\text { Adrenal adenoma } & \cdots \\
\text { Adrenal carcinoma } & \cdots\end{array}$ & $\begin{array}{r}6 \\
17 \\
2 \\
1\end{array}$ & $\begin{array}{l}6 / 6 \\
12 / 17 \\
2 / 2 \\
1 / 1\end{array}$ & $\begin{array}{l}6 / 6 \\
16 / 16 \\
2 / 2 \\
1 / 1\end{array}$ & $\begin{array}{l}1 / 4 \\
2 / 11 \\
2 / 2 \\
-\end{array}$ & $\begin{array}{l}4 / 4 \\
9 / 9 \\
0 / 2 \\
0 / 1\end{array}$ \\
\hline
\end{tabular}
+ That
basal.

pituitary implantation; the diagnosis was based upon the typical clinical features along with the test findings summarized in Table I. There were six patients with obvious pituitary tumours: in five this diagnosis was based upon radiological enlargement of the pituitary fossa (confirmed at necropsy in one), and in the sixth from the presence of oculomotor pareses.

\footnotetext{
* Department of Medicine, Postgraduate Medical School of London. + Department of Radiology, Postgraduate Medical School of London. $¥$ Department of Chemical Pathology, Postgraduate Medical School of London.
}

\section{Tests of Adrenal Function Used}

\section{Urinary Corticosteroids}

The purpose of these tests was to provide evidence of the presence of Cushing's syndrome, and to indicate whether the adrenocortical overactivity was pituitary-dependent or not; clear evidence for such pituitary dependence was taken to imply not only the presence of bilateral adrenal hyperplasia but also the likelihood of a response to pituitary treatment.

Basally.-All patients had at least two basal measurements of urinary corticosteroids ; these were measured initially as 17-oxogenic steroid (Norymberski et al., 1953), and more recently as total 17-oxogenic steroid (Appleby et al., 1955). The upper limits of normal for total 17-oxogenic steroid under basal conditions for adult males and females are quoted as 21 and $16 \mathrm{mg} . / 24$ hours respectively (M.R.C., 1963).

Dexamethasone Suppression Test.-Initially the test was used as described by Slater et al. (1962), in which dexamethasone was given for seven days in a dose of either 0.5 or $1 \mathrm{mg}$. six-hourly and the urinary 17-oxogenic steroid measured on the sixth and seventh days. With this test, in normal and obese subjects, the values fell to $4 \mathrm{mg}$. $/ 24$ hours or below, and usually below $2 \mathrm{mg}$. $/ 24$ hours. Following the report of Liddle (1960) a different procedure was adopted. First, for the purpose of establishing the presence of Cushing's syndrome, a dose of $0.5 \mathrm{mg}$. six-hourly was given and urine samples were collected on the second and third days; Liddle found that the levels fell to below $2.5 \mathrm{mg}$. $/ 24$ hours on the second day in normal subjects. To obtain further evidence of the pituitarydependence of the adrenal overactivity a dose of $2 \mathrm{mg}$. sixhourly was given. All of Liddle's 27 patients with adrenal hyperplasia showed a fall in the urinary 17-oxogenic steroid on this dose, usually to about $50 \%$ of the basal value on the second day, while eight patients with adrenal tumours showed no such suppression. For the present paper, "suppression" was a clear fall in the 17-oxogenic steroid levels from those of the basal values ; this might be complete (as in normal subjects) or incomplete.

Metopirone (Metyrapone) Test.-This test was used and interpreted as described by Liddle et al. (1959, 1962). Metopirone was given in a dose of $500 \mathrm{mg}$. four-hourly for 24 hours and the urinary 17-oxogenic steroid estimated for the day of its administration and for the day after. An increase of the urinary 17-oxogenic steroid of either over $10 \mathrm{mg} . / 24$ hours or a doubling of the basal value was regarded as significant.

\section{Presacral Oxygen Insufflation}

An intravenous pyelogram was done after presacral oxygen insufflation, and plain films and tomograms of the adrenals were then taken.

\section{Implantation Technique and Irradiation Dose}

The implantation technique has already been described (Joplin et al., 1961 ; Hartog et al., 1965). 
For the first eight patients the implants were of ${ }^{198} \mathrm{Au}$ planned to deliver 10,000 rads to the periphery of the pituitary; subsequently we have used combined implants of ${ }^{198} \mathrm{Au}$ and ${ }^{90} \mathrm{Y}$, the activities of each of which were planned to give 5,000 rads to the gland surface. Five patients had repeat implants, in every case using ${ }^{90} \mathrm{Y}$ alone: one had the same dose as in the first implant, three who had pituitary tumours were given doses of $100,000,50,000$, and 50,000 rads at the gland surface ; and the fifth, who had long-standing and very severe disease, received a dose of 100,000 rads to the gland surface.

\section{Results of Urinary Corticosteroid Measurements}

Table I shows the results of the urinary corticosteroid tests performed in a group of 26 patients with Cushing's syndrome, which includes three patients with adrenal tumours, and one with adrenal hyperplasia who was treated by subtotal adrenalectomy because an adrenal tumour was suspected. Patients with adrenal hyperplasia were included in the Table only if the diagnosis was certain either from a clear response to pituitary implantation or from the inspection of the adrenals at operation or necropsy.

All the patients except five had raised basal 17-oxogenic steroid; three of the five exceptions had borderline values (16-17 mg./24 hours), one of these being a boy of 11 in whom the values were raised for his age. The other two had values well within the normal range (11 and $12 \mathrm{mg} . / 24$ hours). All the patients showed an incomplete degree of suppression with dexamethasone $2-4 \mathrm{mg}$./ 24 hours, on which dosage the majority of them scarcely showed any drop in the levels of 17-oxogenic steroid.

Evidence of pituitary-dependence in the patients with adrenal hyperplasia, as indicated by a rise of 17-oxogenic steroid after the administration of Metopirone, was found in all those with bilateral adrenal hyperplasia tested and in neither of those with adrenal tumours tested. Similar evidence based upon some reduction of urinary 17-oxogenic steroid following dexamethasone in a dose of $2 \mathrm{mg}$. six-hourly was obtained in 12 out of 15 patients with bilateral adrenal hyperplasia, the mean fall being $54 \%$ of the basal value (range $0-100 \%$ ). It is important to note that there were three patients with adrenal hyperplasia whose 17-oxogenic steroid showed no fall when given this dose of dexamethasone; it is possible that prolongation of the duration of dexamethasone suppression beyond the three days may have resulted in some suppression of their urinary corticosteroids. One of these three patients had an obvious pituitary tumour. The second had normal basal values, and showed an excellent response to pituitary implantation; the third, on the basis of these results, was thought to have an adrenal tumour, but operation disclosed bilateral hyperplasia. The six patients with obvious pituitary tumours had results which were indistinguishable from those found in the other patients with Cushing's syndrome associated with adrenal hyperplasia.

\section{Results of X-ray Examination of the Adrenals}

Eighteen of the patients had presacral oxygen insufflations performed. In the majority the appearances were consistent with bilateral adrenal hyperplasia, although the exact definition of each adrenal was often poor. In four patients the appearances were suggestive of an adrenal tumour; three of these patients were submitted to adrenal surgery. In two the tumours demonstrated on $x$-ray examination were found, one being associated with adrenal hyperplasia; in the third no adrenal tumours was found. The fourth patient had biochemical evidence of pituitary-dependence and gave a satisfactory response to pituitary implantation; it may therefore be assumed that the lesion producing her Cushing's syndrome was adrenal hyperplasia. Despite being misled on these two occasions we still perform the investigation, since we are anxious not to overlook a tumour, but would not rely on its results alone if the steroid evidence was contrary to that provided by the $x$-ray examination.

\section{Follow-up Review}

In all patients the diagnosis was not regarded as established until retesting three months after implant, when the pituitary dependence of Cushing's syndrome was always reviewed, especially if the response had not been satisfactory.

\section{Results of Pituitary Implantation}

\section{Effects on Cushing's Syndrome}

The overall results are shown in Table II for 20 patients with Cushing's syndrome due to adrenal hyperplasia who have been reassessed after and followed for periods of at least three months. Two of the implanted patients were not reassessed by us, and have not been included. A response has been graded as "satisfactory" when the symptoms disappeared, the facies became normal, frank diabetes was lost or improved, and the basal 17-oxogenic steroid became normal. The response was classified as "partial" if there was a partial clinical remission or correction of the basal 17-oxogenic steroid; patients who initially showed a satisfactory response, but in whom the remission was not sustained, have also been included under this heading.

TABLE II.-Results of First Implants for Partial Pituitary Ablation for Cushing's Syndrome (Followed for 3-54 Months; Mean 15 Months)

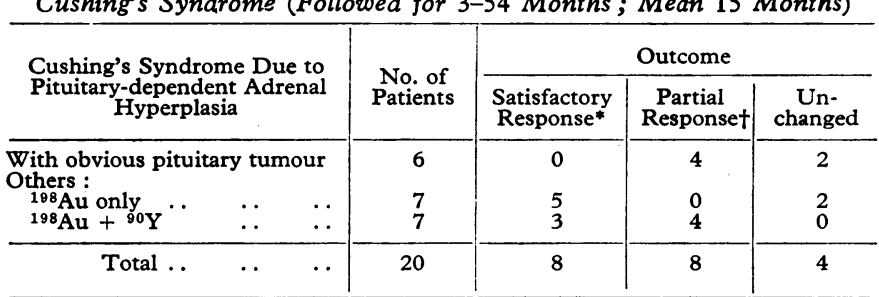

* Satisfactory response $=$ symptom-free, facies normal, glucose-tolerance tes normal or improved, urinary 17-oxogenic steroid normal.

t Partial response = partial loss of clinical sions and symptoms, or correction of urinary 17-oxogenic steroid or response only temporary.

Cases With an Obvious Pituitary Tumour.-Four of the six patients sustained a partial response. Two of them had responses which were initially satisfactory but later relapsed; one of these had oculomotor pareses at the time of the onset of the disease, and the other had a large pituitary fossa on $x$-ray examination but developed an isolated sixth-nerve palsy at the time of the recurrence of the disease. In both these patients it seemed probable that there was an invasive spread of tumour tissue outside the sella turcica. Both these patients had reimplants of ${ }^{90} \mathrm{Y}$ alone with planned peripheral doses of 100,000 and 50,000 rads without any further effect on the Cushing's syndrome, and both had this finally relieved by bilateral total adrenalectomy. One of the patients with a partial response was lost to follow-up, and the fourth had a second implant of 50,000 rads to the gland surface with ${ }^{90} \mathrm{Y}$ alone. Of the two failures, one later had a total adrenalectomy in view of his lack of response to implant, but unfortunately died suddenly six weeks after operation, and the other still has the disease in a mild form and further treatment is under discussion.

Cases Without an Obvious Pituitary Tumour.-Eight out of these 14 patients sustained satisfactory remissions after the first implant. It will be seen that those patients who had the combined implants of ${ }^{198} \mathrm{Au}$ and ${ }^{90} \mathrm{Y}$ did no better than the seven who had ${ }^{198} \mathrm{Au}$ alone. One of the patients who responded satisfactorily was a woman who had a recurrence of her disease. 
accompanied by deep pigmentation, several years after subtotal adrenalectomy ; after the implant she sustained a satisfactory remission of her Cushing's syndrome and lost her excessive skin pigmentation. One patient, aged 11 at the time of his implant, had an initially satisfactory response, with resumption of growth which had previously been arrested ; later, however, he developed signs of a recurrence of the disease, and had a reimplant at the same dose level as the initial implant, but with ${ }^{90} \mathrm{Y}$ alone. A recent assessment at 12 months after this second implant indicated a satisfactory response. Of the two patients who showed no response one was a woman with a very severe and long-standing disease who had a second implant with 50,000 rads to the gland surface from ${ }^{90} \mathrm{Y}$ alone but died three months afterwards from a subarachnoid haemorrhage; the other was a woman with only mild disease who declined further treatment.

\section{Post-implant Corticosteroid Tests}

Table III shows the results of the dexamethasone and Metopirone tests after the first implant in relation to the assessment of the response. It will be seen that all those who had a satisfactory response showed a normal suppression with dexamethasone in a dose of $2-4 \mathrm{mg}$. $/ 24$ hours, and failed to show any response to Metopirone. None of the patients whose condition was unchanged after operation showed a normal suppression with dexamethasone, and all showed a response to Metopirone.

TABLE III.-Corticosteroid-test Results After First Implant for Partial Pituitary Ablation for Cushing's Syndrome

\begin{tabular}{|c|c|c|c|c|c|c|}
\hline \multirow{2}{*}{\multicolumn{4}{|c|}{$\begin{array}{l}\text { Overall Response } \\
\text { to Implant }\end{array}$}} & \multirow{3}{*}{$\begin{array}{c}\begin{array}{c}\text { No. of } \\
\text { Patients }\end{array} \\
\\
8 \\
8 \\
4\end{array}$} & \multicolumn{2}{|c|}{$\begin{array}{c}\text { No. of Subjects Whose Urinary } \\
\text { 17-oxogenic Steroid Shows : }\end{array}$} \\
\hline & & & & & \multirow{2}{*}{\begin{tabular}{|c|}
$\begin{array}{c}\text { Normal Suppression } \\
\text { with Dexamethasone } \\
2 \text { or } 4 \mathrm{mg} . / 24 \mathrm{hr} .^{*}\end{array}$ \\
$6 / 6$ \\
$3 / 8$ \\
$0 / 4$
\end{tabular}} & \multirow{2}{*}{\begin{tabular}{|c}
$\begin{array}{c}\text { No Rise on } \\
\text { Metopironet }\end{array}$ \\
$4 / 4$ \\
$2 / 8$ \\
$0 / 2$
\end{tabular}} \\
\hline $\begin{array}{l}\text { Satisfactory } \\
\text { Partial } \quad . . \\
\text { Unchanged.. }\end{array}$ & $\begin{array}{l}\ldots \\
\ldots\end{array}$ & $\ldots$ & $\because$. & & & \\
\hline
\end{tabular}

† Increasing by $>100 \%$ or $>10 \mathrm{mg}$. 17-oxogenic steroid per 24 hours.

\section{Effects on Other Pituitary Functions}

There were 10 adult pre-menopausal female subjects implanted; all subsequently had periods, whereas four had had prolonged periods of amenorrhoea prior to operation. One patient developed amenorrhoea 15 months after the implant; although there was no other evidence of hypopituitarism, the gonadotrophin excretion was abnormally low (less than 12 mouse units/24 hours), and it must therefore be assumed that the pituitary implant was responsible for the amenorrhoea. One woman became pregnant six months after operation. After implantation the two children who were treated had pronounced spurts of growth. Five patients required corticosteroids; in four this was only in the immediate post-operative period, and therapy was soon discontinued. Only the patient who had previously had a subtotal adrenalectomy required permanent corticosteroid therapy, as in fact had been the case in the early years after her subtotal adrenalectomy for Cushing's syndrome. Two patients who were given second implants, designed to ablate the pituitary, required thyroxine.

\section{Complications}

The complications that have occurred are shown in Table IV. There were four instances of leaks of cerebrospinal fluid; three occurred in patients with obvious pituitary tumours, two of them being after reimplantation designed for total ablation. The one patient who had a C.S.F. drip in the absence of any obvious pituitary tumour had an anatomical anomaly of the subarachnoid space ; at implantation C.S.F. was seen to come from the implant needle when it was in a radiologically satisfactory position in the mid-fossa. All these four patients required surgical treatment with insertion of a muscle strip to stop the leak. There was one patient who developed the unusual complication of a visual-field defect; some months after operation the vision in one eye deteriorated to near blindness, the vision in the other eye being unaffected. The cause of this serious complication was incorrect placing of one seed ; at operation the landmarks had been very difficult to identify owing to the extreme osteoporosis. Two patients developed transient diabetes insipidus.

TABLE IV.-Complications of Pituitary Implantation for Cushing's Syndrome

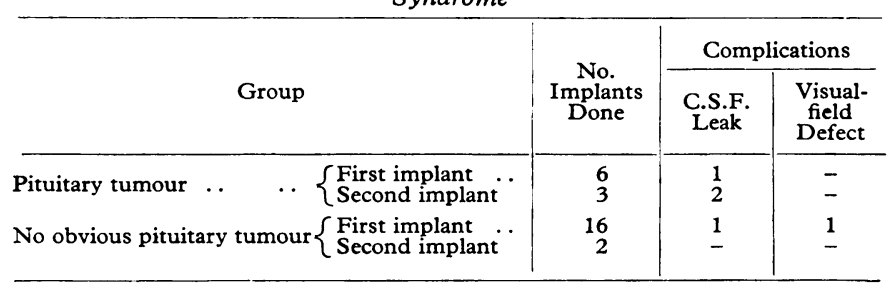

\section{Discussion}

Previous reports of the response of Cushing's syndrome due to adrenal hyperplasia to treatment with deep $x$-ray therapy to the pituitary (Dohan et al., 1957), together with the association of Cushing's syndrome with overt pituitary tumoursfor example, Sprague et al. (1961)-suggested that many, if not all, cases of adrenal hyperplasia may be secondary to pituitary overactivity. Furthermore, remissions have followed pituitary surgery which has been employed in a few cases, often when associated with an obvious pituitary tumour (Luft et al., 1957 ; Ray, 1960). For these reasons we have treated such cases by pituitary implantation of radioactive material, which permits the delivery of a larger dose of irradiation to the pituitary than is possible by external deep $x$-ray therapy. The ideal result of such treatment would be the production of a sustained remission of the disease, without impairing normal pituitary function. Our results for cases with obvious pituitary tumours warrant separate consideration from those without such tumours. Of the six patients with tumours four showed a partial or temporary remission, although in none were these sustained. Two of these patients probably had locally invasive tumours and initially remitted completely, but the others were evidently resistant to radiotherapy. This experience suggests that a larger initial dose of irradiation should be used in such patients, especially if there is any hint of local spread. Here, preservation of normal pituitary function may be of less importance than the need for adequate irradiation of a potentially malignant tumour. Our plan at present is to implant such patients with ${ }^{90} \mathrm{Y}$ alone, giving a peripheral dose of 50,000 rads.

Eight of the 14 patients without obvious pituitary tumours had satisfactory remissions from the initial implant, while four showed a partial response. On the whole this is an encouraging incidence of remissions, and will, we hope, be improved with our present plan of higher dosage implant, which is to give ${ }^{90} \mathrm{Y}$ alone, with a peripheral dose of 20,000 rads. In most patients the implant has not impaired other pituitary function. Menstrual periods have usually been restored or maintained. Pregnancy has occurred in one of our patients. Both children implanted had good spurts of growth after operation. One patient developed amenorrhoea as a consequence of implantation; one patient who had previously had a subtotal adrenalectomy required maintenance corticosteroid therapy ; and two patients required thyroxine after second implants which were planned to ablate the pituitary. Higher doses of ${ }^{90} \mathrm{Y}$ were 
implanted by Molinatti et al. (1960) in a few cases, with satisfactory results.

Implantation may be briefly compared with alternative therapy. Mortality with adrenalectomy was $10 \%$ in 192 operations ' (Mason et al., 1958; Sprague et al., 1961 ; Montgomery and Welbourn, 1963); one-third of 175 patients treated with subtotal adrenalectomy showed recurrence of the disease (Sprague et al., 1961), whereas there was only one recurrence in the 20 patients of Montgomery and Welbourn (1963), but half of these were rendered steroid-dependent. Implantation would seem to be a simpler operation, with, so far, no mortality and only a low risk of hypopituitarism. The remissions which have been reported with external deep $x$-ray therapy have already been mentioned (Johnsen, 1952; Dohan et al., 1957 ; Soffer et al., 1961), while the larger doses which can be given by high-energy heavy-particle beams may yield satisfactory remission rates (Linfoot et al., 1963).

Measurements of corticosteroid levels are essential for the confirmation of the diagnosis of Cushing's syndrome; incomplete suppression of urinary 17-oxogenic steroid after the administration of dexamethasone in doses of $2-4 \mathrm{mg} . / 24$ hours is important evidence in favour of this diagnosis, and all of our patients showed this abnormality. When the diagnosis has been confirmed it is then necessary to establish the source of the disease, which is of particular importance if treatment is to be directed at the pituitary. Here we have used the suppression produced by a dose of dexamethasone of $8 \mathrm{mg}$./day and the Metopirone test. Liddle (1960) found that dexamethasone in this dose suppressed the urinary 17-oxogenic steroid in patients with adrenal hyperplasia, but not in those with an adrenal tumour; however, 2 out of 11 of our patients with proved bilateral hyperplasia failed to show any suppression, and Sprague et al. (1961) have reported a similar lack of suppression in two of their cases. After the administration of Metopirone patients with bilateral hyperplasia have been found to give a normal or exaggerated rise of urinary 17-oxogenic steroid, while patients with adrenal tumours show no such rise (Liddle et al., 1959). This test was done in 12 patients with bilateral hyperplasia and in two with adrenal tumours, and in all instances correctly distinguished the two groups.

It is of interest that all four patients with obvious pituitary tumours who were given Metopirone responded like the other cases of adrenal hyperplasia, a finding also reported by the authors of the test. In addition, we believe it is an important part of the diagnosis of pituitary-dependent adrenal hyperplasia to check the adequacy of the response at three months after implant, and to review the initial diagnosis if no response has occurred.

Dexamethasone and Metopirone tests have also been done after operation and compared with the clinical result of the operation. All the patients tested who had satisfactory clinical responses showed a normal suppression with dexamethasone in a dose of $2-4 \mathrm{mg} . / 24$ hours, and were unresponsive to Metopirone. Conversely, the patients who showed no improvement still showed incomplete suppression with dexamethasone, and still had normal rises of the urinary 17-oxogenic steroid after Metopirone. In contrast, Liddle (1960) found that three out of six patients with a good clinical response to external irradiation of the pituitary still had abnormal resistance to suppression with dexamethasone, and Futterweit et al. (1962) reported two similar cases. Metopirone unresponsiveness was also found by Liddle et al. (1962) in all their seven successfully irradiated cases, but not by Futterweit et al. (1962). Doubtless sufficient lowering of A.C.T.H. production would produce Metopirone unresponsiveness, while dexamethasone might be expected to be more effective in suppressing the A.C.T.H. output from the pituitary gland whose A.C.T.H. secretion has been decreased. It may be found that the measurement of the response to dexamethasone and Metopirone is of value in the assessment of the outcome of the treatment of Cushing's syndrome by irradiation of the pituitary, but clearly more cases need to be studied.

\section{Summary}

Twenty cases of Cushing's syndrome due to bilateral adrenal hyperplasia have been treated by partial pituitary ablation, using needle implantation of radioactive gold or yttrium seeds, singly or in combination. The results of urinary 17-oxogenic steroid measurements during dexamethasone and Metopirone (metyrapone) tests before and after operation are described, and their value in demonstrating pituitary-dependence before implant, and in assessing the remission afterwards, is discussed. Of 14 patients without obvious pituitary tumours the response to first implant was satisfactory in eight, and there was a partial response in four. Of the six patients with obvious pituitary tumours four showed a partial response. There was no evidence of hypopituitarism after operation, apart from one patient who developed amenorrhoea. Complications were mainly in the patients with obvious pituitary tumours, where three patients developed cerebrospinal-fluid leak, in two after a second implant; in the other 13 cases there was one C.S.F. leak due to an anatomical anomaly. There was also one instance of visual damage due to operative misplacement.

We would like to express our thanks to the Department of Medical Physics, Hammersmith Hospital, for invaluable assistance in calculating the dosimetry of implants.

\section{REFERENCES}

Appleby, J. I., Gibson, G., Norymberski, J. K., and Stubbs, R. D. (1955). Biochem. 尹., 60, 453.

Dohan, F. C., Raventos, A., Boucot, N., and Rose, E. (1957). f. clin. Endocr., 17, 8.

Futterweit, W., Krieger, D. T., and Gabrilove, J. L. (1962). Ibid., 22, 364.

Hartog, M., Doyle, F., Fraser, R., and Joplin, G. F. (1965). Brit. med. 7., $1,396$.

Johnson, S. G. (1952). Acta med. scand., 144, 165.

Joplin, G. F., Fraser, R., Steiner, R., Laws, J., and Jones, E. (1961). Lancet, 2, 1277 .

Liddle, G. W.' (1960). 7. clin. Endocr., 20, 1539.

Estep, H. L., Kendall, J. W., Williams, W. C., jun., and Townes, A. W. (1959). Ibid., 19, 875 .

Island, D., and Meador, C. K. (1962). Recent Progr. Hormone Res., 18, 125.

Linfoot, J. A., Lawrence, J. H., Born, J. L., and Tobias, C. A. (1963). New Engl. F. Med., 269, 597.

Luft, R., Olivecrona, H., Ikkos, D., and Hernberg, C. A. (1957). Acta endocr. (Kbh.), 24, 1.

Mason, A. S., Richardson, J. E., and King, C. E. (1958). Lancet, 2, 649. Medical Research Council (1963). Ibid., 1, 1415.

Molinatti, G. M., Camanni, F., and OOlivetti, M. (1960). Acta endocr. $(K b h), 34,323$.

Montgomery, D. A. D., and Welbourn, R. B. (1963). Clinical Endo-

crinology for Surgeons, p. 97. Annold, London.
Norymberski, J. K., Stubbs, R. D., and West, H. F. (1953). Lancet, 1, 1276.

Ray, B. S. (1960). F. Neurosurg., 17, 1.

Slater, J. D. H., Hartog, M., Fraser, R., and Rantzen, B. (1962). Brit. med. Ұ., 1,1584 .

Soffer, L. J., Iannaccone, A., and Gabrilove, J. L. (1961). Amer. F. Med., 30, 129.

Sprague, R. G., Weeks, R. E., Priestley, J. T., and Salassa, R. M. (1961). Gardiner-Hill, p. 84. Butterworth, London. 